\title{
The State of Design - A Comprehensive Literature Review to Chart the Design Science Research Discourse
}

\author{
Rahul Thakurta \\ XIMB, Xavier University, \\ India \\ rahul@ximb.ac.in
}

\author{
Benjamin Mueller \\ University of Groningen, \\ the Netherlands \\ b.mueller@rug.nl
}

\author{
Frederik Ahlemann \\ David Hoffmann \\ University of Duisburg-Essen, University of Duisburg-Essen, \\ Germany \\ Germany \\ frederik.ahlemann@uni-due.de david.hoffmann@uni-due.de
}

\begin{abstract}
Design science is an increasingly popular research paradigm in the information systems discipline. Despite a recognition of the design science research paradigm, questions are being raised about the nature of its existence and its contributions. Central to this argument is the understanding of the relationship between "theoretical research" and "design research" and the necessary implications for design. In this research, we contribute to this discourse by carrying out a structured literature review in order to appreciate the current state of the art in design science research. The results identify an incongruence between the methodological guidelines informing the design and how the design is carried out in practice. On the basis of our observations on the design process, the theoretical foundations of design, and the design outcomes, we outline some research directions that we believe will contribute to methodically well-executed design science contributions in the future.
\end{abstract}

\section{Introduction}

Design science research (DSR) has become an important approach in information systems (IS) research. The goal of the DSR paradigm is to create artifacts to address problems that have an impact on IS research and practice and to generate new knowledge about and insights into a class of problems [13, 19]. Following the seminal article by Hevner et al. [17], DSR is increasingly acknowledged as an alternative to behavioral science research in the IS field. Moreover, the start of an international conference on design science research in information systems and technology (DESRIST) in 2006 suggests the emergence of a specialized community within the IS community specifically concerned with integrating and advancing the design community's discourse. Also, a number of special issues in journals like EJIS, JAIS, and MISQ, as well as specialized tracks at the mainstream IS confer- ences such as ICIS, ECIS, and HICSS, are evidence of the DSR paradigm's increasing popularity.

The fundamental principle of DSR is that knowledge and understanding of a design problem and its solution are acquired by building and applying an artifact [16]. In the DSR context, the term artifact implies a construction that applies information technology (IT) to organizational tasks [26]. Design is often a complex process, and designing valuable artifacts is challenged by the need for creative progress in domain areas where the existing solutions and theories are often insufficient. In order to be seen as valuable, contributions in DSR are often required to demonstrate both the novelty and the utility of the artifacts [27]. At the same time, the explication of design knowledge is an additional step toward formalizing it as a theory, which Gregor [11] coined as theories for design and action (type V).

Despite the recognition of the DSR paradigm as an essential part of IS research, we observe a number of deliberations questioning DSR's nature of existence and its contribution to the domain $[5,51]$. The central argument characterizing these conversations is the demarcation of theoretical research, which constitutes natural science and behavioral research, and design research, which is intended to solve problems in practice $[12,31]$. We believe that the attention devoted to segregating these two complicates our understanding of how they relate to each other.

In this research, we propose to undertake a structured literature review to understand some of the design-related issues in a DSR project. Such a literature review also helps to aggregate and facilitate existing knowledge and develop newer insights [39, 49]. We want to go beyond prior analyses of the DSR literature and explore what links to theory are exhibited in extant DSR either as a foundation or as an outcome of the research. More in particular, we want to answer the following three research questions:

1. What are the theoretical underpinnings researchers use to ground their DS research? 
2. How do researchers achieve theoretical contributions beyond the development of an artifact or design theory?

3. What methodical approaches are chosen to link behavioral and design research and design the artifact?

The findings presented in this paper represent the outcome of the first phase of a larger project by which we intend to develop suggestions for how the IS discipline can better utilize the theoretical body of knowledge for design activities and "exploit" the theoretical potential of design research. Here, we carry out a first diagnosis of the current state of the art through a descriptive analysis that allows us to see how today's DSR projects are grounded, carried out and produce certain outcomes.

The remainder of the article is structured as follows: Section 2 discusses related theoretical evidence from the design science domain. Section 3 presents the framework we use for data collection and analysis. Section 4 describes our research method. In section 5, we present our findings, which are subsequently discussed in section 6. Finally, section 7 summarizes our contribution, discusses the limitations of our work, and outlines future work.

\section{Related work}

Existing contributions in IS have analyzed various aspects of the DSR paradigm, for example, the design process $[4,9,23,24,35]$, artifact types created [17, $33,30]$, and evaluation methods used [34, 37, 43]. These articles present generic guidelines with respect to methodical aspects of DSR in relation to designing an artifact or capturing the design knowledge.

There have been efforts to demonstrate the DSR paradigm's state of the art based on literature reviews. Indulska and Recker [20] present a literature analysis to identify the proliferation, nature, and quality of DSR at IS conferences. Apart from showcasing the prominence of design science, their results also demonstrate methodical weaknesses in real-world design science contributions. Piirainen et al. [36] present another review on design science and identify the limitations of relating the knowledge contributions of DSR endeavors to their results. Heinrich and Riedl [15] investigate the dominance and advocacy of the design-oriented research approach in the Central European IS (Wirtschaftsinformatik) community and advocate for the use of a "theory-driven design approach" as a viable strategy for the future. Similarly, Leukel et al. [25] carry out a literature review to understand the usage of DSR in the business \& infor- mation systems engineering community in Germanspeaking countries. The results indicate a low level of theoretical underpinning, which points to a lack of rigor in DSR endeavors.

Based on the evidence cited above, even though the discourse on DSR's foundations, methodical approaches, and scripts appear to be mature, there seem to be some limitations with respect to what is generally proposed and what is practiced in real-world DSR projects, which is a point that our research addresses.

\section{Proposed framework}

Figure 1 depicts our framework, which serves as a guideline for data collection and analysis. The framework outlines the process of design in response to an identified problem, and has been conceptualized based on evidence from existing DSR publications. Problem solving has been generally acknowledged as a process where the problem solver carries out a solution search to identify a solution path [14]. The solution search process in response to a design problem has also been acknowledged $[4,38]$. The search process contributes to the grounding (i.e. design rationale) of the resultant DSR artifacts $[23,14]$. The end result of the design is a form of design contribution that can range from abstract artifacts (e.g., theories) to material artifacts (e.g., instantiations) [13].

The ordering of the four components of the framework integrate the design process from the problem conceptualization stage to the result demonstration stage and form the basis for generating the codes relevant to our research issues. The problem is a representation of the differences between the desired situations and the existing situation [45]. Solution search involves an exploration of various approaches to the problem and is informed by existing evidences on related issues [23]. The design rationale includes the justifications governing the design of the artifact under consideration. The contribution box addresses design outcomes that may range from specific instantiations in the form of products and processes to more general (i.e., abstract) contributions in the form of nascent design theory (e.g., constructs, design principles, models, methods, and technological rules) to well-developed design theories about the phenomena under study [12].

The boxes represented under the heading "categories and concepts" (Figure 1) represent the theoretical concepts (as bullets) informing derivation of the codes during content analysis, and their grouping as categories corresponding to the identified framework components. For example, we categorize design problems originating in IS based on a classification presented by Sidorova et 
al. [44] which the authors term as research themes that summarize the intellectual core of the IS discipline. This categorization permits identification of existing DSR focus areas in IS. We discuss all the categories and codes along with the findings in section 5. ment and the predominance of publications focused on design research in these outlets. For the conferences, we focused our selection on papers published in design science or a strongly related track.

We further specified a temporal boundary condition of 10 years, ranging from January 2004 to December

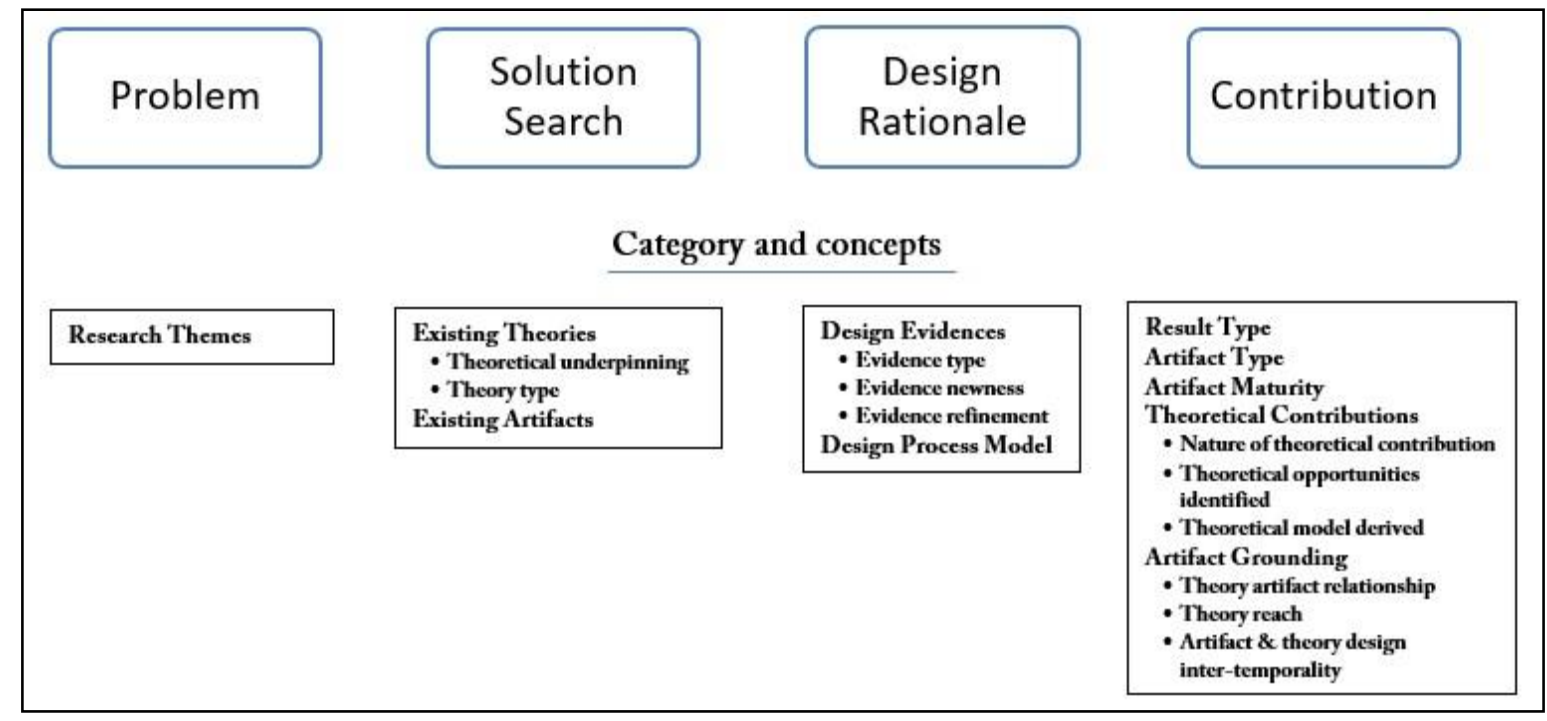

Figure 1. A framework for understanding design issues in DSR

\section{Research method}

We use content analysis to identify and analyze articles related to design science. Content analysis provides a systematic approach to describe and classify text material [8]. Guided by our analytical framework (Figure 1), two researchers carried out a structured review of the identified articles. During the analysis, the initial analysis team developed a codebook. The codebook, which contains definitions and examples, was subsequently refined through discussions with two additional researchers and emerging consensus among all four researchers. In the end, the codebook comprised 11 categories $^{1}$ and related concepts following the framework.

In order to identify the articles to be included in this structured review, we focused our attention on four of the leading IS journals, as well as some of the most pertinent IS conferences (Table 1). The journals covered here are part of the AIS Senior Scholars' Basket of Journals. ${ }^{2}$ These specific journals in our review were shortlisted based on their mission state-

\footnotetext{
${ }^{1}$ Ten categories (Figure 1) along with article description (name of journal/conference, publication year, volume/proceeding number)

${ }_{2}^{2}$ https://aisnet.org/?SeniorScholarBasket
}

2013. The starting year was influenced by the publication of the seminal article on design science by Hevner et al. [17]. Within this specified set, we used the search string "design AND (science OR theory OR research)" to find occurrences in the papers' title, abstract, and keywords. The articles returned by the search query were further screened for appropriateness concerning fit with our framework. For example, we included articles that dealt with construction or evaluation of design science artifacts in the context of identified IS design problems. Conceptual articles and articles taking a metatheoretical approach were excluded from the review.

\section{Table 1. Data sources}

\begin{tabular}{|c|c|}
\hline 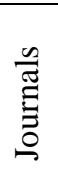 & 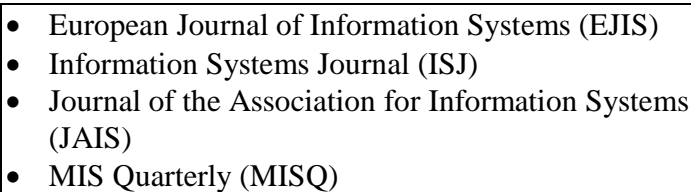 \\
\hline 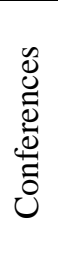 & $\begin{array}{l}\text { International Conference on Design Science Re- } \\
\text { search in Information Systems and Technology } \\
\text { (DESRIST) } \\
\text { - European Conference on Information Systems } \\
\text { (ECIS) } \\
\text { - International Conference on Information Systems } \\
\text { (ICIS) }\end{array}$ \\
\hline
\end{tabular}


Additionally, conference papers were considered only in cases in which the findings were not published in a subsequent conference or a journal article. Based on the screening results, we were able to shortlist 275 articles for full-text review.

We created a spreadsheet template with individual columns assigned to each of the codes used in the analysis. Before coding, the research team examined the codebook to ensure consistency in interpretation. Furthermore, for the sake of consistency, the authors also independently examined a sample of codes pertaining to articles from different channels during coding. The team discussed cases of disagreement and resolved them. This approach ensured that either an agreement was reached regarding the coding of the data or new codes were developed that satisfied everyone and met the objectives of the research. During data analysis we created sub-samples for journal and conferences papers and contrasted them. In case of significant differences, we will report on them in the following sections.

\section{Findings ${ }^{3}$}

\subsection{Background information}

Table 2 provides a breakdown of where the 275 articles (49 journal articles and 226 conference papers) included in this review are from. The results indicate that conference proceedings feature DSR endeavors more (82\%) than journals (18\%). ICIS proceedings have published the largest number of articles on design science (40\% overall), followed by DESRIST conference proceedings (31\% overall).

Table 2. Data source breakup

\begin{tabular}{|l|c|}
\hline Journal / Conference & Count \\
\hline Journal Articles & $\mathbf{4 9}$ \\
\hline EJIS: 4, ISJ: 6, JAIS: 20, MISQ: 19 \\
\hline Conference Proceedings & $\mathbf{2 2 6}$ \\
\hline DESRIST: 86, ECIS: 30, ICIS: 110 \\
\hline
\end{tabular}

Figure 2 shows the distribution of these publications across years. The year-wise distribution of articles indicates that more than $60 \%$ of the articles on design science research have been published since 2010, which highlights the level of attention the domain has been receiving lately from researchers

\footnotetext{
${ }^{3}$ Evidence of articles following the results presented in this section are available from the authors on request.
}

worldwide. In the following subsections, we provide our results pertaining to the framework components presented in Figure 1.

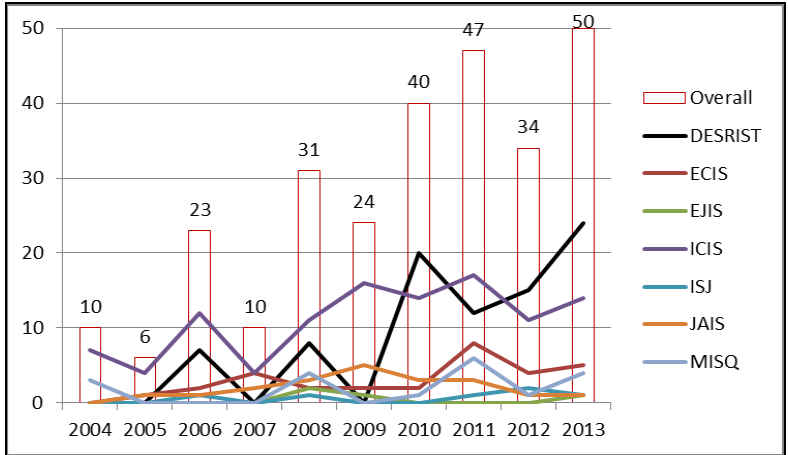

Figure 2. Publication trend across years

\subsection{Problem context}

As mentioned above, we classified the IS design problems into five research themes i.e., IT and organizations, IS development, IT and individuals, IT and markets, and IT and groups [44]. Results based on the 275 shortlisted articles demonstrate a distribution across problem domains (Figure 3).

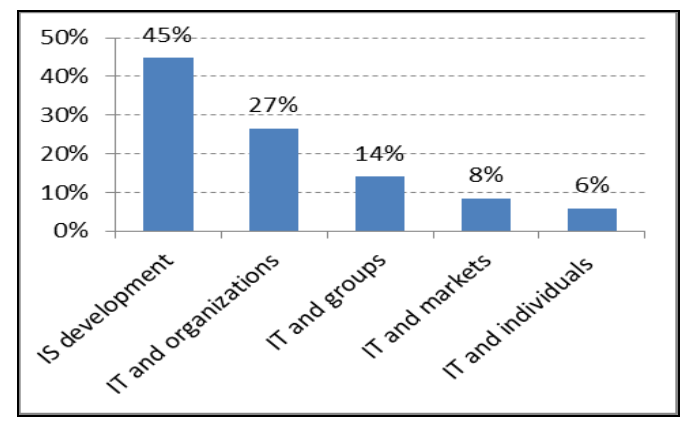

Figure 3. Occurrence of problem domains

Design problems related to the IS development context are found to make up the largest portion of the sample $(45 \%)$. The DSR endeavors here mostly focus on the technical aspects associated with IS design. The secondlargest problem context relates to IT and organizations (27\%) where the emphasis is on designing artifacts for application and using IS in organizational contexts. The remaining papers were categorized as IT and groups (14\%), IT and markets (8\%), and IT and individuals $(6 \%)$. The predominance of the IS development problem context in the result can be an outcome of overemphasis on IT artifacts with the publications getting routed to more technology-oriented journals [1]. 


\subsection{Solution search}

The solution search component examines evidence that design science researchers have used to justify the grounding of the various design contributions (discussed in section 5.5). The nature of the evidence can be existing theories or existing artifacts that, as the terms suggest, have been documented in prior literature. The existing theories category comprises two concepts. The first concept theoretical underpinning addresses the nature of the design's foundation (i.e. argumentative/single theoretical abstraction/multiple theoretical abstractions). The second concept theory type classifies theoretical abstractions as grand (i.e. broader in scope and more abstract), mid-range (i.e., theory with limited scope and explaining a specific set of phenomena), and substantive theories (i.e., a "working theory" of action for a specific context).

The theoretical underpinning of the design approach is observed to be mostly argumentative in 225 cases $(82 \%)$ with design justifications based on referencing associated literature. In the remaining 50 instances, the design is motivated based on single theoretical abstraction (13\%) or multiple theoretical abstractions (5\%). In these cases, the type of theoretical abstraction is found to be largely mid-range (45\%), whereas substantive (32\%) and grand theories (23\%) are used less frequently.

In 221 instances, the DSR endeavor resulted in instantiations that are artifacts representing processes or products assumed to be complete. Out of these, only in 67 instances (30\%) does the design benchmark similar artifacts from literature or build upon existing artifacts. In the remaining cases, authors have either mentioned the existence of similar artifacts in a discreet manner without any further discussion or ignored it completely.

\subsection{Design rationale and design process}

The design rationale component examines the nature of design evidence governing the proposed artifact design, as well as the design process model that was followed. Design evidence includes three concepts: Evidence type ascertains whether the artifact design has been justified based on theoretical abstractions, artifacts, or argumentative reasoning on literature; evidence newness identifies whether the concerned evidence is a new contribution to the literature; and evidence refinement identifies whether the evidence was revised during the justification of the proposed design.

In 33 instances, the artifact is found to be guided by kernel theories. ${ }^{4}$ Kernel theories are theories from natural or social sciences governing design requirements [50]. In 40 instances, the design rationale of the solution can be traced to artifacts of various nature: models (21), methods (7), and others (12) comprising architecture (1), framework (7), guidelines (1), logic (1), meta-model (1), and principle (1). In nine (logic: 1, model: 7, metamodel: 1) of these 40 instances, the artifact evidence is a new contribution in the sense that it is proposed in the concerned article and then used as the basis for the underlying design. In the remaining cases, either the design rationale is justified based on argumentation or is unspecified. Additionally, in four instances (framework: 1, model: 1, kernel theory: 2), the evidence was refined toward proposing the solution.

In terms of the usage of specific process models underlying design, in $43 \%$ of the cases (i.e., 95 out of 221 instances of design of a complete artifact), the authors made no reference to any process model. We noted the use of process models from existing literature in only $28 \%$ of the cases. In the remaining cases, the article concerned proposed new process models or used a blend of methods or process models for the design of the particular artifact.

\subsection{Contribution}

The contribution component examines various facets of DSR outcomes and encompasses the categories' result type, artifact type, artifact maturity, theoretical contributions, and artifact grounding.

We classified the type of result as design theory, abstract design, and instantiations (Table 3). Design theories are sets of primarily prescriptive statements that describe how a class of artifacts should behave (metarequirements) and how they can be constructed [50]. In the case of abstract design, the connection between the design and its goals is not specified. Instantiation captures artifacts where the design can be assumed to be complete. Out of the 52 instances (19\%) of an abstract design, in 23 cases an instance of the design was formally presented. Similarly, in 44 out of the 275 instances (16\%), the contribution of the article is a design theory with a corresponding instantiation in 20 cases. In one DSR instance, an abstract design was proposed at the outset and subsequently extended into a design theory.

\footnotetext{
${ }^{4}$ In one instance (i.e., Voigt et al. [48] ), the DSR endeavor combines design theories from the domain of investigation as a kernel theory to 5
} 
Table 3. Result type classification ${ }^{5}$

\begin{tabular}{|l|c|c|c|}
\hline & \multicolumn{2}{|c|}{ Instantiation } & \multirow{2}{*}{ Total } \\
\hline Type & No & Yes & \\
\hline & - & $178(81 \%)$ & $\mathbf{1 7 8}$ \\
\hline Abstract Design & $29(54 \%)$ & $23(11 \%)$ & $\mathbf{5 2}$ \\
\hline Design Theory & $24(44 \%)$ & $20(9 \%)$ & $\mathbf{4 4}$ \\
\hline Both & $1(2 \%)$ & - & $\mathbf{1}$ \\
\hline Total & $\mathbf{5 4}$ & $\mathbf{2 2 1}$ & $\mathbf{2 7 5}$ \\
\hline
\end{tabular}

Lastly, instantiation of an artifact as the sole contribution of an article is noted in 178 cases (65\%).

Similarly to March and Smith [26], we classified the type of the artifact as constructs, methods, models, and others (additional artifact types). Table 4 presents the results of the classification. Software instantiations represent the cases where the concerned artifact is a ready-to-use instance and is implemented. The most frequently used artifact type is method $(43 \%)$, followed by model $(22 \%)$ and constructs $(7 \%)$. In 60 cases $(21 \%)$, a software instance of the corresponding artifact was instantiated. A breakdown of the artifacts grouped together under the "others" type reveals some additional artifact types, which are shown in Table 5. Data indicates that system $(48 \%)$ and framework $(22 \%)$ are the predominant types of artifacts constituting the "others" category. The diversity of these artifacts showcases the novelty of DSR contributions and further extends the IT artifact typology [17]. In 16 articles, authors proposed multiple DSR artifacts, which leads to a total number of occurrences of 293 (and not 275).

Table 4. Artifact type classification ${ }^{5}$

\begin{tabular}{|l|c|c|c|}
\hline & \multicolumn{2}{|c|}{$\begin{array}{c}\text { Software } \\
\text { Instantiation }\end{array}$} & \multirow{2}{*}{ Total } \\
\cline { 1 - 3 } Artifact Type & No & Yes & \\
\hline Construct & $19(8 \%)$ & $1(2 \%)$ & $\mathbf{2 0}$ \\
\hline Method & $96(41 \%)$ & $29(48 \%)$ & $\mathbf{1 2 5}$ \\
\hline Model & $56(24 \%)$ & $9(15 \%)$ & $\mathbf{6 5}$ \\
\hline Others & $62(27 \%)$ & $21(35 \%)$ & $\mathbf{8 3}$ \\
\hline Total & $\mathbf{2 3 3}$ & $\mathbf{6 0}$ & $\mathbf{2 9 3}$ \\
\hline
\end{tabular}

In terms of the maturity of the 293 proposed artifacts, about 81 artifacts $(28 \%)$ are ready to use, of

\footnotetext{
${ }^{5}$ Percentage figures within Tables 3, 4, and 6 express relative proportion with respect to the corresponding column totals.
}

which 60 have been implemented using some tool (Table 4). In total, 157 artifacts (54\%) are incomplete in the sense that they require some kind of modification prior to use. In the case of the remaining 55 artifacts (18\%), the artifact is mostly abstract, or the artifact maturity cannot be inferred from the particular article.

Table 5. Breakdown of other artifacts

\begin{tabular}{|l|c|c|c|}
\hline & \multicolumn{2}{|c|}{$\begin{array}{c}\text { Software } \\
\text { Instantiation }\end{array}$} & \multirow{2}{*}{ Total } \\
\cline { 1 - 3 } Artifact Type: Others & No & Yes & \\
\hline Application & 1 & 3 & $\mathbf{4}$ \\
\hline Architecture & 5 & 1 & $\mathbf{6}$ \\
\hline Design Pattern & 1 & - & $\mathbf{1}$ \\
\hline Framework & 17 & 1 & $\mathbf{1 8}$ \\
\hline Infrastructure & 1 & - & $\mathbf{1}$ \\
\hline Methodology & 6 & 1 & $\mathbf{7}$ \\
\hline Ontology & 1 & - & $\mathbf{1}$ \\
\hline Portal & 1 & - & $\mathbf{1}$ \\
\hline Process Model & 1 & - & $\mathbf{1}$ \\
\hline System & 26 & 14 & $\mathbf{4 0}$ \\
\hline System Landscape & - & 1 & $\mathbf{1}$ \\
\hline Taxonomy & 1 & - & $\mathbf{1}$ \\
\hline Typology & 1 & - & $\mathbf{1}$ \\
\hline Total & $\mathbf{6 2}$ & $\mathbf{2 1}$ & $\mathbf{8 3}$ \\
\hline
\end{tabular}

Table 6. Nature of theoretical contributions ${ }^{5}$

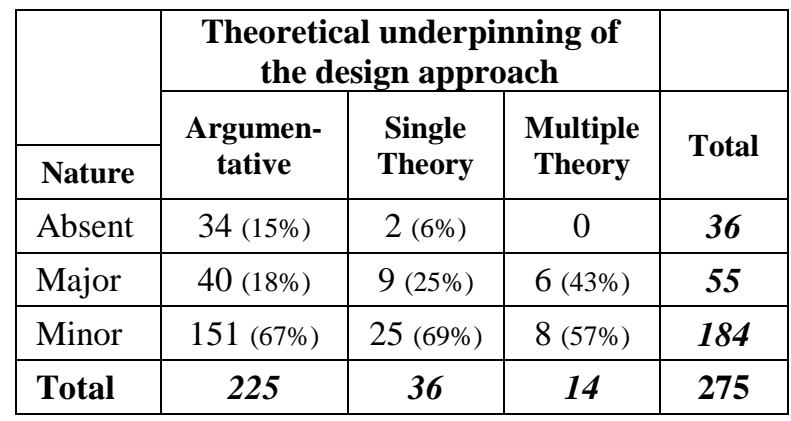

Inspired by Colquitt and Zapata-Phelan [6], we distinguish between high and low theoretical contributions of the papers in our review. Transposing this logic onto our DSR sample, we classified the nature of theoretical contributions to the DSR endeavors as major (i.e., implying theoretical conclusions that are new or invalidate previously established results) or minor (i.e., theoretical conclusions that confirm, extend or modify previously 
Table 7. Breakdown of theory artifact relationship

\begin{tabular}{|l|c|}
\hline Theory Artifact Relationship & Count \\
\hline No Theory & 57 \\
\hline Argumentative / Anecdotal Evidence $\rightarrow$ Artifact & 102 \\
\hline Existing Theory $\rightarrow$ Artifact & 28 \\
\hline Theory Building $\rightarrow$ Artifact & 23 \\
\hline Parallel Development & 9 \\
\hline (Explorative) Artifact $\rightarrow$ Theory & 2 \\
\hline Total & $\mathbf{2 2 1}$ \\
\hline
\end{tabular}

established results). We present the results in Table 6 classified with respect to the theoretical underpinning of design approach dimensions discussed in section 5.3. Leaving out the 36 articles (13\%) where theoretical conclusions were not evident, a majority of articles shows minor contributions $(67 \%)$. The predominance of minor contributions in DSR endeavors using an argumentative rationale to inform the design context is also evident. Major theoretical contributions can be noted in 55 instances $(20 \%)$ and can be observed to be the likely outcome of DSR endeavors grounded in multiple theoretical abstractions.

In order to understand the temporal relationship between theory and artifact in a DSR endeavor, we analyzed the 221 articles reporting instantiations of artifacts. Table 7 presents our findings. Data indicates that in 57 instances (26\%), the design of the artifact is not based on any theoretical abstractions. In 102 instances (46\%), the design of the artifact is based on argumentative deductions or links to anecdotal evidence from literature. In 28 instances (13\%), the artifact design is based on existing theoretical abstractions proposed in prior publications. In 23 instances $(10 \%)$, the DSR endeavor proposes a theory that is subsequently used in the design of the artifact. In nine instances $(4 \%)$, parallel construction of theory and artifact can be noted in the articles. In these cases, the same DSR endeavor proposes a theoretical abstraction and also a linked instance of an artifact. Lastly, in two instances, the concerned DSR endeavors proposed an artifact in an explorative manner (i.e., based on related evidence from literature) and then extended the contribution in the design of a theoretical abstraction.

An analysis of how the theory has been applied and used in the construction of the artifacts indicates that in 106 out of the 221 instantiations (48\%), the artifact was designed by argumentatively linking evidence from the literature. In 57 cases (26\%), the artifact design is theory-based. In these cases, either the artifact design has been motivated by some theoretical abstractions or the design is deduced from a theoretical core (existing/new). In the remaining 58 cases (26\%), there is no evidence of how the theory has been used or applied in artifact construction.

Table 8. Contribution of theory in artifact design

\begin{tabular}{|l|c|}
\hline Theory Contribution in Artifact Design & Count \\
\hline Artifact Effects Explained (A) & 13 \\
\hline Artifact Environment Relationship Explained (B) & 21 \\
\hline Internal Mechanics Explained (C) & 84 \\
\hline Loosely Motivated (D) & 45 \\
\hline Total & $\mathbf{1 6 3}$ \\
\hline
\end{tabular}

The contribution of the theory in artifact design for the 163 instances (i.e., leaving out the 58 cases mentioned above where the use or application of theory in artifact design in unspecified) is tabulated in Table 8. In 84 instances (C) (51\%), the contribution of the theory has been to explain or deduce the internal structure of the artifact concerned. In 21 instances (B) (13\%), the theory contributes toward explaining the relationship between the artifact and its environment. Taken together, results (B) and (C) demonstrate that the role of theory in artifact design has been mostly explanatory (i.e., type II of Gregor's [11] theory types). The 13 instances (A) $(8 \%)$ represent type III theory, where the theory contributes to predicting the effect of the artifact. In the remaining 45 instances $(28 \%)$, the contribution of theory in artifact design is either unspecified or cannot be adequately inferred from the articles. A snapshot of how theoretical abstractions have influenced the design of artifacts in the 221 articles reporting instantiation of artifacts is presented in Table 9, along with DSR publication examples. The table indicates a predominant argumentative grounding of artifacts and the contribution of theory in the corresponding designs.

\section{Discussion}

The results of our study provide a comprehensive account of the current state of the art in DSR, where we have analyzed the theoretical foundations of design, the design process, and the design outcomes. The findings offer substantive ways in which to rethink how DSR is carried out in the real world. We anchor our discussion to the following three pivots: design method/process, theoretical foundations, and theoretical contributions that are central to most of the scholastic recommendations on how to carry out a DSR study. 


\begin{tabular}{|c|c|c|c|c|}
\hline $\begin{array}{l}\text { Theoretical } \\
\text { Underpinning }\end{array}$ & $\begin{array}{l}\text { Theory } \\
\text { in Artifacts }\end{array}$ & Theory-Artifact Relationship & Count & Examples \\
\hline \multirow[t]{9}{*}{ Argumentative } & \multirow[t]{4}{*}{ Argumentative } & (Explorative) Artifact $\rightarrow$ Theory & 1 & Andersson and Keller [2] \\
\hline & & $\begin{array}{l}\text { Argumentative / Anecdotal } \\
\text { Evidence } \rightarrow \text { Artifact }\end{array}$ & 92 & van Steenbergen et al. [47] \\
\hline & & Parallel Development & 1 & O'Flaherty et al. [32] \\
\hline & & Theory Building $\rightarrow$ Artifact & 2 & Mayer [28] \\
\hline & \multirow[t]{2}{*}{ No Evidence } & (Explorative) Artifact $\rightarrow$ Theory & 1 & Mustafa and Sjöström [29] \\
\hline & & No Theory & 57 & Delfmann and Knackstedt [7] \\
\hline & \multirow[t]{3}{*}{ Theory-based } & Existing Theory $\rightarrow$ Artifact & 4 & Paul and Opal [10] \\
\hline & & Parallel Development & 5 & Schütz et al. [41] \\
\hline & & Theory Building $\rightarrow$ Artifact & 16 & Hjalmarsson and Rudmark [18] \\
\hline \multirow[t]{4}{*}{$\begin{array}{l}\text { Single / Mul- } \\
\text { tiple Theories }\end{array}$} & Argumentative & $\begin{array}{l}\text { Argumentative / Anecdotal } \\
\text { Evidence } \rightarrow \text { Artifact }\end{array}$ & 10 & Jasimuddin et al. [21] \\
\hline & \multirow[t]{3}{*}{ Theory-based } & Existing Theory $\rightarrow$ Artifact & 24 & Shrestha et al. [42] \\
\hline & & Theory Building $\rightarrow$ Artifact & 5 & Scholten et al. [40] \\
\hline & & Parallel Development & 3 & Kohler and Fueller [22] \\
\hline
\end{tabular}

Table 9. Use of theoretical abstraction in artifact design

Design method/process:

Our study results indicate mostly an argumentative approach toward conceptualizing and designing artifacts. Design of artifacts is found to be carried out in an arbitrary manner without reference to any process models in 95 instances (see section 5.4). This can be observed to be more prevalent for DSR contributions featuring in conference proceedings (84 instances). These observations are contrary to the recommendations from design researchers to reflect on methodological guidelines in order to achieve the intended design [35, 46]. The deviances from the methodological guidelines may be attributed to the complexities of the DSR research methods (i.e. prescribing adherence to specified guidelines at all stages of the design science study but limited recipes for conducting the research [5]), and associated time and effort requirements vis-a-vis, the provocation of a faster turnaround as a conference article of the intended contribution.

\section{Theoretical foundations:}

Justifications of the design of artifacts can be observed to be based on theoretical abstractions, artifacts (existing or newly proposed), and argumentative reasoning and empirical justifications (see section 5.4). The theoretical grounding is also found to be mostly mid-range and substantive theoretical abstractions. Only in $12 \%$ of the articles under review were kernel theories specified to inform the artifact design. The corresponding proportion in case of journal contributions is found to be higher (27\%). These results indicate departure from the traditionally prescribed grounding of artifacts where kernel theories are assumed to be the starting point of artifact construction (e.g., Kuechler \& Vaishnavi [23]). The evidences presented in Table 9 substantiates an argumentative grounding of the designed artifacts, and more so for contributions featuring in conference proceedings (not shown). The solution search process in these cases reveals the artifact design to be based on existing artifacts proposed earlier, which is a finding that has hitherto gone unreported. These various kinds of justifications of the proposed artifacts can be the result of an inadequate appreciation of the nature and value of foundations governing the design.

Theoretical contributions:

The results of the DSR endeavors are observed to be design theories, abstract designs, artifacts, and software instantiations (Tables 3 and 4). Design theories represent a more mature form of knowledge and correspond to the level 3 knowledge contribution type [12]. Abstract designs and artifacts are level 2 contributions, which are less mature than level 3. Finally, level 1 constitutes software instantiations (Table 4), and these represent situated implementations of the artifacts. From the results, we could also identify artifacts at different levels of maturity, ranging from early stage artifacts to complete instantiations (see section 5.5), with the pattern of occurrence consistent across journals and conferences (not shown). We believe that these contributions generally stem from a lack of appreciation of what constitutes a good artifact from a scientific perspective and the absence of clarity on whether the DSR endeavor should focus on the design alone or the knowledge contributions. 


\section{Conclusion}

This paper presents a literature review to understand the research rigor in current DSR studies by analyzing the theoretical foundations of design, the design process, and the design outcomes. The results highlight the lack of rigor with regard to carrying out DSR projects in a methodical fashion.

Our study offers scope for further research. An extension of our work could focus on understanding the various streams and tenets in current DSR approaches. We report on variations in certain results between journals and conferences, and an in-depth analysis of the differences may uncover interesting patterns. Second, the fact that some of the prevalent intuitions about DSR actually seem to be wellfounded might emphasize the need for further development of a common body of design knowledge - a kind of a theory of design. While many design researchers might express skepticism toward such a formalization of DSR, unity in method and paradigm is often identified as a key common denominator of a strong field [3]. Third, future research may further inspect in detail the dualism in DSR [50] where theories and artifacts can be viewed as complementary entities intertwined in the design process. Our findings may motivate design researchers to intertwine design and theory in different ways in order to justify, the role that the theories play in the relevant design. Fourth, research scope also exists in terms of analyzing how the observations we have put forward translate into detailed and actionable methodological recommendations for design researchers.

Our work is not without limitations. First, the relevance of the articles included in the review can be questioned. However, we deliberately limited the set of outlets reviewed here in order to ensure feasibility. Second, our methodological analysis was based on the authors' description within the paper. Hence, if the design details were not articulated or implied in the paper, then it was assumed that the published research did not follow them. Finally, our content analysis is prone to typical hermeneutic biases. In our analysis of the papers, we are constrained to an understanding of what we think the papers' original authors wanted to express through their writing as published. We believe, however, that the consensual process in which we challenged each other's understanding and documented emergent, shared understanding in our codebook helped to address this issue to the best of our abilities.

We hope that our research will motivate scholars to adopt methodologically sound, theoretically strong and methodically well-executed design science contributions and in the process contribute more meaningfully to the DSR paradigm and the larger body of theory.

Acknowledgement. The authors would like to thank Philip Quaebicker for his contribution in the project.

\section{References}

[1] T. C. Albert, P. B. Goes and A. Gupta, "Gist: a Model for Design and Management of Content and Interactivity of Customer-Centric Web Sites", MIS Quarterly, 28 (2004).

[2] B. Andersson and C. Keller, Harness mobility: managing the off-task property, Global Perspectives on Design Science Research, Springer, 2010, pp. 258-269

[3] C. Banville and M. Landry, "Can the Field of MIS be Disciplined?" Communications of the ACM, 32 (1989), pp. 48-60

[4] R. Baskerville, J. Pries-Heje and J. Venable, Soft Design Science Methodology, Proceedings of the 4th International Conference on Design Science Research in Information Systems and Technology, Philadelphia, PA, USA, 2009.

[5] R. L. Baskerville, M. Kaul and V. C. Storey, "Genres of inquiry in design-science research: Justification and evaluation of knowledge production", Mis Quarterly, 39 (2015).

[6] J. A. Colquitt and C. P. Zapata-Phelan, "Trends in theory building and theory testing: A five-decade study of the Academy of Management Journal ", Academy of Management Journal, 50 (2007), pp. 1281-1303.

[7] P. Delfmann and R. Knackstedt, "Towards tool support for information model variant management-a design science approach", (2007).

[8] B. Downea-Wamboldt, "Content analysis: method, applications, and issues", Health care for women international, 13 (1992), pp. 313-321

[9] A. Gehlert, M. Schermann, K. Pohl and H. Krcmar, Towards a Research Method for Theory-Driven Design Research, in H. R. Hansen, D. Karagiannis and H.-G. Fill, eds., 9. Internationale Tagung Wirtschaftsinformatik (WI 2009), 2009.

[10] P. Golding and O. Donaldson, "A design science approach for creating mobile applications", ICIS 2009 Proceedings.

[11] S. Gregor, "The Nature of Theory in Information Systems", MIS Quarterly, 30 (2006), pp. 611-642.

[12] S. Gregor and A. R. Hevner, "Positioning and presenting design science research for maximum impact", MIS Quarterly, 37 (2013).

[13] S. Gregor and D. Jones, "The Anatomy of a Design Theory", JAIS, 8 (2007), pp. 313-335.

[14] J. R. Hayes, Cognitive psychology: Thinking and creating, Brooks/Cole Pub Co, 1978.

[15] L. J. Heinrich and R. Riedl, "Understanding the dominance and advocacy of the design-oriented research approach in the business informatics community: a history-based examination", Journal of Information Technology, 28 (2013).

[16] A. Hevner and S. Chatterjee, Design research in information systems: theory and practice, Springer Science \& Business Media, 2010. 
[17] A. R. Hevner, S. T. March, J. Park and S. Ram, "Design Science in Information Systems Research", MIS Quarterly, 28 (2004), pp. 75-105.

[18] A. Hjalmarsson, D. Rudmark and M. Lind, "When designers are not in control-experiences from using action research to improve researcher-developer collaboration in design science research", Global Perspectives on Design Science Research (2010), pp. 1-15.

[19] J. Iivari, "The IS core-VII: Towards information systems as a science of meta-artifacts", Communications of the Association for Information Systems, 12, 2003.

[20] M. Indulska and J. Recker, "Design science in IS research: a literature analysis", Information Systems Foundations, 285-303 (2010).

[21] S. M. Jasimuddin, N. Connell and J. H. Klein, "Knowledge transfer frameworks: an extension incorporating knowledge repositories and knowledge administration", Information Systems Journal, 22 (2012), pp. 195-209.

[22] T. Kohler, J. Fueller, K. Matzler and D. Stieger, "Cocreation in virtual worlds: the design of the user experience", MIS quarterly, 35 (2011), pp. 773-788

[23] W. Kuechler and V. Vaishnavi, "A Framework for Theory Development in Design Science Research - Multiple Perspectives", Journal of the Association for Information Systems, 13 (2012), pp. 395-423.

[24] J. Lee, J. Pries-Heje and R. Baskerville, Theorizing in Design Science Research, in H. Jain, A. Sinha and P. Vitharana, eds., Service-Oriented Perspectives in Design Science Research, 2011.

[25] J. Leukel, M. Mueller and V. Sugumaran, The State of Design Science Research within the BISE Community: An Empirical Investigation, ICIS 2014 Proceedings.

[26] S. T. March and G. F. Smith, "Design and natural science research on information technology", Decision Support Systems, 15 (1995), pp. 251-266.

[27] S. T. March and V. C. Storey, "Design science in the information systems discipline: an introduction to the special issue on design science research", MIS Quarterly, 2008.

[28] R. C. Mayer, J. H. Davis and F. D. Schoorman, "An integrative model of organizational trust", The Academy of Management Review, 20 (1995), pp. 709-734.

[29] M. I. Mustafa and J. Sjöström, Design principles for research data export: lessons learned in e-health design research, Design Science at the Intersection of Physical and Virtual Design, Springer, 2013, pp. 34-49

[30] R. C. Nickerson, U. Varshney and J. Muntermann, "A method for taxonomy development and its application in information systems", Eur J Inf Syst, 22 (2013).

[31] B. Niehaves, On epistemological diversity in design science: New vistas for a design-oriented IS research, ICIS 2007.

[32] B. O'Flaherty, A. Pope, C. Thornton and S. Woodworth, Capturing multi-stakeholder needs in CustomerCentric Cloud Service Design, ICIS 2013 Proceedings.

[33] P. Offermann, S. Blom, M. Schönherr and U. Bub, Artifact types in information systems design science - a literature review, Global perspectives on design science research, Springer, 2010, pp. 77-92
[34] K. Peffers, M. Rothenberger, T. Tuunanen and R. Vaezi, Design science research evaluation, Design science research in information systems. Advances in theory and practice, Springer, 2012, pp. 398-410

[35] K. Peffers, T. Tuunanen, M. A. Rothenberger and S. Chatterjee, "A design science research methodology for information systems research", Journal of management information systems, 24 (2007), pp. 45-77

[36] K. Piirainen and R. Briggs, Design Theory in Practice Making Design Science Research More Transparent, in $\mathrm{H}$. Jain, A. Sinha and P. Vitharana, eds., Service-Oriented Perspectives in Design Science Research (DESRIST 2011), Springer, Berlin \& Heidelberg, Germany, 2011, pp. 47-61.

[37] J. Pries-Heje, R. Baskerville and J. Venable, Strategies for design science research evaluation, 2008, pp. 255-266.

[38] J. Pries-Heje, R. Baskerville and J. R. Venable, "Strategies for design science research evaluation", (2008).

[39] F. Rowe, "What literature review is not: diversity, boundaries and recommendations", European Journal of Information Systems, 23 (2014), pp. 241-255

[40] U. Scholten, C. Janiesch and C. Rosenkranz, Inciting Networks Effects through Platform Authority: A Design Theory for Service Platforms, ICIS 2013 Proceedings.

[41] A. Schutz, "Concept and Theory Formation in the Social Sciences", The Journal of Philosophy, 51 (1954).

[42] A. Shrestha, A. Cater-Steel, M. Toleman and W.-G. Tan, A decision support tool to define scope in IT service management process assessment and improvement, Design Science at the Intersection of Physical and Virtual Design, Springer, 2013 [43] K. Siau and M. Rossi, "Evaluation techniques for systems analysis and design modelling methods - a review and comparative analysis", Information Systems Journal, 21 (2011).

[44] A. Sidorova, N. Evangelopoulos, J. S. Valacich and T. Ramakrishnan, "Uncovering the intellectual core of the information systems discipline", Mis Quarterly, 32 (2008).

[45] H. A. Simon, The sciences of the artificial, Cambridge, MA, USA, 1981.

[46] V. K. Vaishnavi and W. Kuechler, Design science research methods and patterns: innovating information and communication technology, CrC Press, Boca Raton, 2008.

[47] M. Van Steenbergen, R. Bos, S. Brinkkemper, I. Van De Weerd and W. Bekkers, The design of focus area maturity models, Global Perspectives on Design Science Research, Springer, 2010, pp. 317-332

[48] M. Voigt, B. Niehaves and J. Becker, Towards a unified design theory for creativity support systems, Design science research in information systems. Advances in theory and practice, Springer, 2012, pp. 152-173

[49] J. Vom Brocke, A. Simons, B. Niehaves, K. Riemer, R. Plattfaut and A. Cleven, Reconstructing the giant: On the importance of rigour in documenting the literature search process, Proceedings of the 17th European Conference on Information Systems Italy, 2009, pp. 2206-2217.

[50] J. G. Walls, G. R. Widmeyer and O. A. El Sawy, "Assessing Information System Design Theory in Perspective: How Useful was our 1992 Initial Rendition?" Journal of Information Technology Theory and Application, 6 (2004).

[51] R. Winter, "Design Science Research in Europe", European Journal of Information Systems, 17 (2008). 